\title{
Liminality, disruption, and change: A prismatic look at pandemic education
}

\author{
Marni E. Fisher ${ }^{1}$ (D) Meredith A. Dorner $^{2}$ D $\cdot$ Kimiya Sohrab Maghzi $^{3}$ (D) \\ Charlotte Achieng-Evensen ${ }^{4}(\mathbb{D}) \cdot$ Leslie C. Whitaker $^{5}$ (D) Frances Hansell $^{6}$ (D) \\ James St. Amant ${ }^{7}$ (D) Susan M. Gapinski ${ }^{8}$ (D)
}

\begin{abstract}
Using prismatic inquiry, a team of researchers documented a variety of personal experiences that spanned elementary through higher education, with the goal of determining what helped and what was needed to improve the adaptability of our educational system during the Covid-19 emergency. Three analytical teams identified that students remained at the heart of the conversation, supported by leadership, teachers, parents, and the students themselves. Furthermore, all four groups needed, in differing ways: (a) connection, (b) voice, (c) social-emotional skills, and (d) academic knowledge.
\end{abstract}

Keywords Covid-19 $\cdot$ Teaching $\cdot$ Pandemic education $\cdot$ Leadership $\cdot$ Students

Marni E. Fisher

mfisher@saddleback.edu

Meredith A. Dorner

mdornder@ivc.edu

Kimiya Sohrab Maghzi

kimiya_maghzi@redlands.edu

Charlotte Achieng-Evensen

cevensen@dusd.net

Leslie C. Whitaker

lcwhitaker@capousd.org

Frances Hansell

frances.hansell@svusd.org

James St. Amant

jamesst.amant@gmail.com

Susan M. Gapinski

suzygap@aol.com

1 English Department, Saddleback College, 28000 Marguerite Parkway, Mission Viejo, CA 92692, USA 
The Covid-19 emergency had an impact on the whole world by spring 2020. Educators at all levels of education, plus parents and students, found themselves learning new technology while trying to shift learning largely from face-to-face to online "pandemic" learning. The pandemic curriculum was holistic and called for a research framework, such as prismatic inquiry, which is designed to look at the whole curriculum, including what is explicit, hidden, and sociocultural (Fisher 2016). This included building a team of researchers interested in documenting a variety of personal experiences, which spanned elementary through higher education, with the goal of determining what helped and what was needed to improve the adaptability of our educational system.

\section{Current literature}

Pandemic education (which may also be referenced as distance learning, eLearning, pandemic learning, or distance education) is atypical of the regular online learning structures previously found in higher education; instead, it is a form of emergency eLearning (Nordmann et al. 2020). While some see the innovations developed in online learning as an opportunity to improve education (Knysh and Dudziak 2020), others caution that emergency eLearning should not be normalized as a replacement for face-to-face learning (Murphy 2020).

\section{Student supports}

Educational programs that surveyed students were better able than were programs that did not survey students to align changes in teaching methods with students' learning (Coyne et al. 2020) and identify students' expectations (Loda et al. 2020). Recognizing that various factors have an impact on students, institutions of higher education made changes to schoolwork structures (Johnson et al. 2020) and evaluation processes (Nordmann et al. 2020). This included fewer class sessions and advocating for synchronous and asynchronous contact. Struggling and marginalized students needed additional digital resources (Molea and Năstasă 2020). With on-campus spaces no longer available, campus-based student resources needed reviewing and replacement. In addition to developing digital competence, successful online learning included active engagement, hope, and community (Coyne et al. 2020). Maintaining mental health became important as pandemic driven stress, anxiety, and depression increased (Lakhan et al. 2020).

2 School of Life Sciences and Technologies, Irvine Valley College, 5500 Irvine Center Drive, Irvine, CA 92618, USA

3 College of Teaching and Learning, University of Redlands, 1200 East Colton Ave, P.O. Box 3080, Redlands, CA 92373, USA

4 Attalah College of Educational Studies, Chapman University, One University Drive, Orange, CA 92866, USA

5 Capistrano Unified School District, San Juan Capistrano, CA, USA

6 Saddleback Valley Unified School District, Mission Viejo, CA, USA

7 Apple Valley Unified School District, Apple Valley, CA, USA

8 Union Ironworker, Local 433, Fullerton, CA, USA 


\section{Educator supports}

Even when programs increased technical supports, educators faced shortages in digital knowledge and access to technical tools for teaching online (Coyne et al. 2020). This was matched by the difficulties in translating face-to-face into online instruction and was further compounded by the lack of preparation time for this transition (Yusoff et al. 2020). Additional supports needed for educators included integrating ways to connect and build professional community and lenience to cope with personal impacts from the pandemic, including vulnerable populations, such as educators responsible for small children (Coyne et al. 2020; Nordmann et al. 2020).

\section{Educational needs}

The initial transition from in-person to online instruction varied widely across and within different education levels. Higher education's typical leadership preferences undermined speedy and effective decision making (Coyne et al. 2020). Schools need resiliency to handle an online transition and processes to suppress virus transmission (De Giusti 2020). Additional resources may include consultation and communication systems and improved technology to prioritize online sessions and reduce burnout and screen fatigue (Coyne et al. 2020; De Giusti 2020; Dogar et al. 2020). School improvements might include critical examination of race, racism, equity, and inclusion and accommodations for impacted students (Coyne et al. 2020; De Giusti 2020). In higher education, different processes are needed to support tenured, junior, and adjunct faculty. Furthermore, for research dependent on graduate student assistance, clear procedures and protocols are needed to determine the priority level of continuing on campus research projects (Coyne et al. 2020).

\section{Conceptual framework}

Recognizing that education is a complicated endeavor that is "wicked" rather than simple to examine, prismatic theory was designed for educational research, rejecting the one-size-fits-all patterns of education (Fisher 2016; Rittel and Webber 1972; Shaffer 2001). Emerging out of Deleuze and Guattari's (1987) rhizomatic theory and influenced by mass-observation (Stanley 2001), the framework deliberately engages a multifaceted lens rather than a reductionist lens to break up hegemonic and "arborescent" patterns through deterritorialization. This perspective aligns with the goal of mapping rather than retracing previous paths.

\section{Methodology and study design}

As a methodology, collaborative prismatic inquiry gathers a variety of perspectives to both tell a story and identify multiple facets of a phenomenon across subjects, levels, and/or positions (Achieng-Evensen et al. 2017). Prismatic inquiry is designed to examine what the dominant narrative hides. Drawing from many theoretical and methodological roots, it allows for crossing boundaries as well as layers in perspective and analysis (Fisher 2016). In this study, experienced teams layered approaches and experiences from different methodological expertise, which strengthened the study, identifying elements that might have been missed otherwise. Furthermore, while prismatic inquiry may start with a driving 
question, the influences of grounded theory (Glaser and Strauss 1967), particularly when paired with rhizomatic theory and mass-observation, mean prismatic inquiry is just as likely to journey toward a final research question.

The weakness of prismatic inquiry is that it draws from contemporary surrealism (Fisher 2013), arts-based research (Leavy 2009), and practitioner action research (Anderson et al. 2007). The influences of contemporary surrealism and arts-based research give the methodology a metaphorical power of flight - a way to examine the unseen, the hidden, and the intuitive - through Eisner's (1991) additional forms of language. However, the integration of surrealism (Breton 1936) and methodologies that move away from traditional forms or flirt with alternative methodologies may undermine it against the more established research cannon.

Researcher participants were invited for their variety of experiences and perspectives during the educational transition forced by the implementation of Covid-19 social distancing and quarantine procedures. Twelve researchers were invited to the study, and eight committed to join the research team:

1. Kindergarten through grade-8 administrator and undergraduate professor (English)

2. Graduate-level professor (education) and mother

3. Teacher specialist and program coordinator and lecturer

4. Undergraduate professor (biology and anthropology) and parent

5. Tykes-Kindergarten through grade- 6 principal

6. Elementary special education teacher

7. Elementary teacher

8. Parent

Each researcher participant was given the same prompt: "Write one to two pages about your perceptions of teaching during the Covid-19 emergency teaching transition: (1) what is working, (2) what needs to be improved, and (3) your overall impressions of teaching during Covid-19". Guidelines on the prompt were deliberately loose, allowing for a minimum response without a maximum of structure or rules.

The texts covered a variety of perspectives, and each researcher took a different approach to the prompt. Then the researchers with experience and interest in analysis met to decide a form of analysis. In alignment with collaborative prismatic inquiry (AchiengEvensen et al. 2017), the researchers with experience with analysis decided to divide examine the data three ways, with different individuals or teams taking a different approach. The purpose behind this layered analysis was to examine the information through multiple lenses, which not only produces preliminary results for each set of lenses but also layers the analysis and multiplicity of results to gather a better picture before culminating in overall findings.

\section{Analytic strategies}

Using the prompt to examine perspectives on what worked, what was still needed, and personal perspectives on the Covid-19 transition aided in identifying answers to the question of, "How can curricula respond to fast-changing, unpredictable, and often disruptive events, such as the Covid-19 outbreak?" The first team mapped data through NVivo 
word frequency, the second through narrative, and the third through charted codes and annotations.

The first team chose a two-cycle data analysis process. The first cycle involved reading, analysis for common words (Saldaña 2013). The most common word, "student", was highlighted, and all texts were read, using an intuitive lens looking for a sense of each text's overall big picture (Stern 2007). The second cycle involved running the text through NViVo and analyzing word frequency.

The second team chose a two-cycle data analysis process. The first cycle involved reading separately each participant piece, using a grounded theory approach to generate codes for "initial cycle coding" (Saldaña 2013). In the second cycle, researchers moved through the segments of the data to identify repeated words and ideas. This review provided the basis for exigent ideas. This second cycle of coding supported grouping generative themes from the data. Partner groups met to compare codes and generated themes in order to find commonalities. The categories that emerged from the comparative conversations became the basis for the second team's findings.

The third team used coding for themes and meaning categorization (Rallis and Rossman 2011). The first reading developed initial codes. Annotating the texts and revisiting the codes clarified emerging patterns. Overall notes about each piece of data were recorded, then triangulated to check common patterns (Anderson et al. 2007). This was a cyclical or rhizomatic process, and data were revisited as new patterns emerged. This prismatic process, which also echoed grounded theory, aided in developing clarity and understanding.

\section{Research findings}

Taking three approaches that were deliberately different engaged differing perspectives and the prismatic lens. Attempts to align findings across analysis groups resulted in occasional overlaps, while highlighting different parts of the data, requiring all viewpoints to develop results. Therefore, the research findings identify the commonalities across teams and then explore what each team found.

\section{Commonalities across teams}

All three teams identified a category that could be tied to pedagogy, whether they named it innovation, learning, or teaching. The first and second teams identified technology and online as important codes. The second and third teams also aligned on the importance of organization or preparation, communication, and collaboration.

\section{Team 1: Word analysis}

Team 1 used NVivo to code for the words most frequently used in the texts, checking word frequency. After doing this, the team reviewed the manuscripts, looking for the word student, since this central word appeared most frequently throughout everyone's writing (Figure 1).

Looking at word variations adjusted counts slightly, but the focus on students remained central. Five additional words were highlighted across all the participants: students, school, teaching, learning, and learning online. Parents were also important to this dialogue (Table 1). 


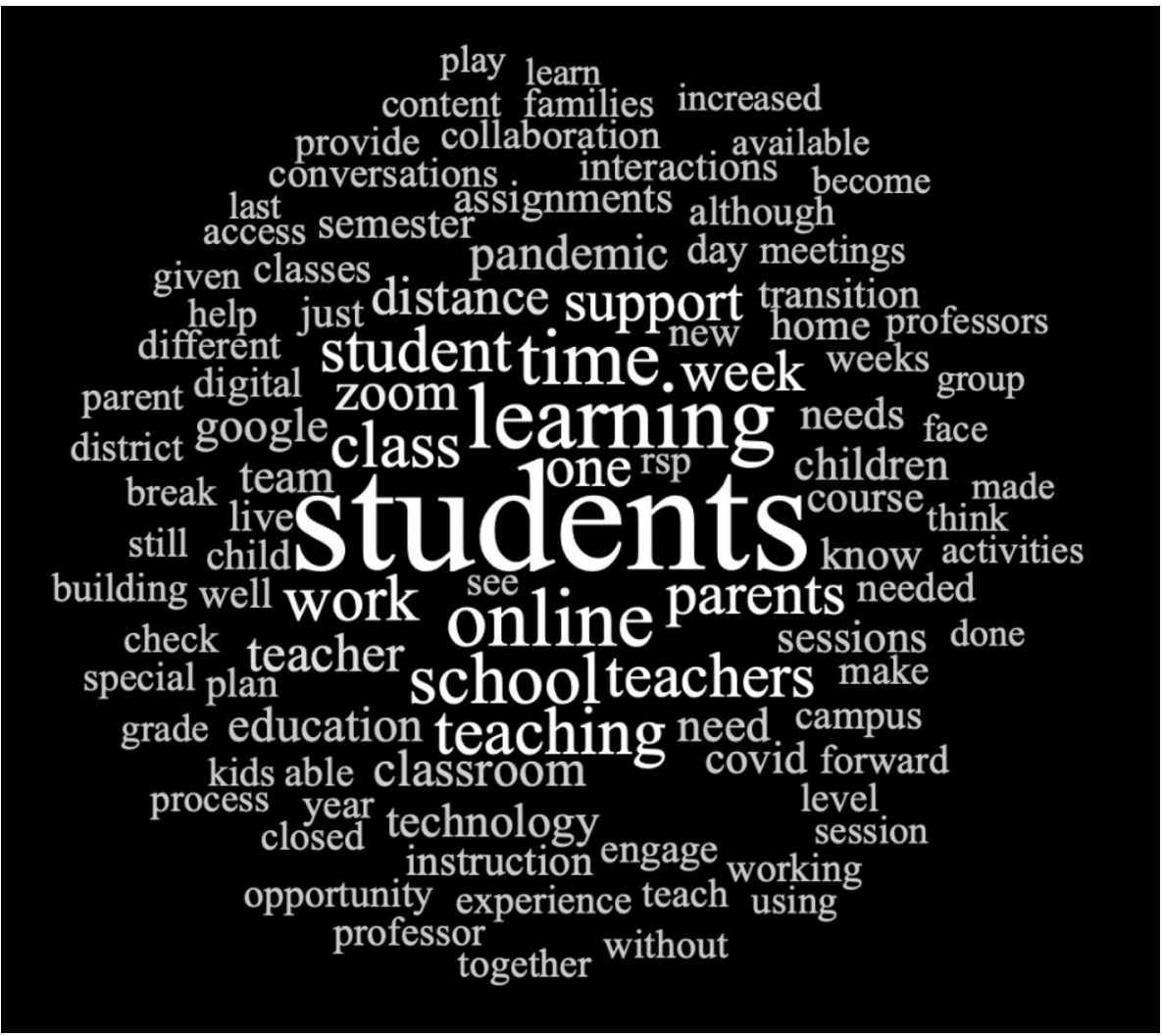

Figure 1 Frequency word cloud

Table 1 Student reference counts

\begin{tabular}{llll}
\hline Roles & \multicolumn{2}{l}{ Referenced words } & \multirow{2}{*}{ Percentage (\%) } \\
\cline { 2 - 3 } & Student(s) & Kid & Your children \\
\hline K-8 admin and undergraduate professor (English) & 54 & 6 & 2.33 \\
Graduate-level professor (education) and mother & 16 & & 2.13 \\
Teacher specialist and program coordinator & 23 & 2.13 \\
Undergraduate professor (biology and anthropology) & 16 & & 3.07 \\
TK-6 principal & 12 & & 2.24 \\
Elementary special education teacher & 27 & & 3.74 \\
Elementary teacher & 41 & & 4.55 \\
Parent & 1 & 4 & 0.24 \\
\hline
\end{tabular}

Pandemic education also was, as expected, a large component of this discussion as well as the flexibility and transition required for this process to occur. Many referred to a systematic process for the transition, the flexibility of educators, and their ability to learn new 
approaches and innovative ways. The opportunity for collaboration in higher education increased, while the digital equity gap was amplified.

\section{Team 2: Qualitative coding}

Team 2, with their line-by-line coding, identified eight overarching themes. These themes were (a) organization/structure, (b) underlying relationships between students and faculty, (c) communication, (d) collaboration, (e) flexibility, (f) technology, (g) teacher innovation, and (h) social-emotional support for students.

The first theme, organization/structure, indicated the importance for all educators explicitly formalizing their approaches to distance learning. Subthemes included teacher organization, structure and routine created for students, and the need for teacher preparation time. One teacher said, "I found that my time with students was so precious, and I had to be tightly planned for the Zoom sessions". This aided the development of structure and routine so important for students: "I created a study plan for each week, for each class, that detailed, step by step, everything students should do for that week (watching lectures, readings, accessing worksheets, completing labs, discussions, etc.)".

The need for teacher preparation time was important for success. Sometimes this required the district or school to provide the time and training for educators. One participant said, "Teachers were on campus for the week, and selected families interacted with teaching teams while they tested out new technology in order to see what would be most effective for maintaining educational standards and learning".

Two educators talked about how the school took time to prepare teachers, and the parent noted how, at first, no one knew what to do, but after the first 2 or 3 weeks, the teachers were trained and prepared, so the rest of the academics flowed smoothly. The educational leader also recommended multiple measures for developing a routine with students to parents while promising, "As much as we can create a routine schedule with you, and provide structure for families, that is our goal for everyone". While this pandemic seemed to come out of nowhere, schools where administration had kept track of worldwide events had some foresight:

We were given weeks of warnings before the campus closed and kept up to date. I had time to talk to my live class and plan with them over various scenarios of how the class wanted to adjust class attendance.

Overall, participants expressed a definite need to recognize the increased amount of organization and preparation to develop the structures and routines to support students.

The second theme was the underlying relationships between educators and students because schooling involves more than academics: "More and more, it becomes apparent that students, in the midst of the pandemic, are present in online sessions where they feel most connected to their teachers. If this connection does not exist, students' attendance is sporadic". Connection was important to students' success. When relationships were already established before the pandemic, students' success continued. Furthermore, students expressed the need to connect with the educators whom they missed:

It would be easier to just make lunch at home, but seeing Mrs. S and Mr. T is important to my son, so we go, every day. We make signs for them, and he relishes those small exchanges that he gets to have with them. 
The third theme, clear communication, included subthemes of parent engagement, personal communication/relationship with parents, good communication with students, collaboration between teacher and parents, communication with parents, student conferences, and increased parent communication. Some educators found connecting one-on-one or in a combination of whole group and small groups was helpful for some students: "I have a love-hate relationship with individual student conferences. I find them exhausting, but they keep students moving forward and the results are unquestioningly positive". Furthermore, the special education teacher stated, "I also shared with parents, that I would be available to them, their students, and their students' teachers to be a resource and support for anything to complete their general education class work during this time". For special education, the increase in interaction between educators and parents was important: "One silver lining in all of this has been the increase of interaction that I have experienced with my student's parents". However, creating this engagement pattern was not universal to educators: "Some students and families were easier to engage than others".

The fourth theme, collaboration, was important for all educational levels. Educators commonly identified that, as one participant stated, "a huge part of successful online learning is collaboration".

The fifth theme was flexibility, which included the ability of the school to adapt to the transition. One educator said, "By now, as K-12 educators, we are settled into a distance learning mode. Our entire system pivoted to meet the immediate needs of student". This ability to shift in order to focus on the needs of the student was present at the district, educator, and parent levels.

The sixth theme, technology, was not unexpected, since it had become the major tool for conveying education. Success, however, varied. One participant identified, "Some teachers, generally younger in the field, are armed with already formed technology usage practice. They are adept at integrating and embedding digital tools as a core component of support instruction". It helped when teachers already had preparation and skills, and furthermore, had developed technological skills with students and parents: "Teachers were already trained in using Google classroom, and while there was some variation by grade level, most parents were used to checking online for assignments". In one instance, the reminder was given to parents: "We have talked a lot about 21 st-century skills for decades now, and this is an opportunity for us as educators to benefit from reflection and greater communication with colleagues who are excited about adapting and thriving". This receptivity to technology, once it had become the only option, increased overall, as did educator access to instructional technology supports providing training.

The seventh theme identified as helpful was teacher innovation. While one educator cited experience with the need to shift and change, another identified that "teachers are becoming more innovative and creative in their approach to teaching. Assignments have becoming highly engaging and often require parents to accompany their little ones as they explore concepts and complete the assigned tasks". Furthermore, one educator noticed a point of joy in teaching: "And finally, in some cases... I have observed several unexpected bright spots to this situation... I have had the pleasure of receiving truly meaningful positive feedback from my students". This capacity for innovation, which diminished under scripted lessons early in the millennium (Ede 2006), became more important under Common Core (CCSSSO and NGA Center 2010) and aided some educators during the pandemic transition.

The eighth theme, the social-emotional well-being of students during the pandemic, was an area of major concern. One participant stated, "When it became apparent that the schools would close for the remainder.... we had one hurdle to get over before we could 
find our equilibrium, and that was dealing with the emotional well-being of our children". This included concern for the social-emotional well-being of students as well as parents, and the additional needs of students in special education: "The emotional well-being of children needs to be addressed. Children with special needs need to be given extra help". These social-emotional needs were also of concern in general education and higher education, as stated by one participant who saw "the concerns of students feeling they can't be successful in the current environment". In higher education, students were informally surveyed by some educators as part of their teaching practices: "The feedback was largely positive. It seems that most of those students felt that I was supporting them well". Also important was recognizing the social-emotional needs of the educators: "As educators, we are also traumatized by this experience, too. We need to forgive ourselves when we fall part, when trauma affects our thinking, or when we cannot be productive".

\section{Team 3: Story-specific and global focus}

Team 3's cyclical process resulted in two major foci. These included the story specifics of each writer and global patterns.

Story-specific focus

In the first story, the K-8 administrator and undergraduate professor focused on the importance of preparation and on integrating structures at the faculty and student level that supported flexibility, technology, and authentic collaboration. The focus on correct preparation spanned both K-8 and college.

There were a lot of things that we did right... a singular focus on collaboration... grade level teams have regular time to focus on student data across the grade level. Teachers were already trained in using Google Classroom, and, while there was some variation by grade level, most parents were used to checking online for assignments.

Students' voices in decisions at all levels aligned with the literature (Harper 2020; Midcalf and Boatwright 2020), as did collaboration (Nordmann et al. 2020).

Liminality for educators, parents, and students was addressed through previous experience and building of social-emotional supports. Supported routines and connections were important, as well as pedagogy, recognition of inequality, and the need for differentiation. Of note is that the educator took over another professor's course toward the end of the semester, only to find that both students and professor had been struggling due to a lack of transitioned content, connection, and flexibility. Students at all levels missed social connections.

The second story, which was that of the graduate professor (education) and mother, focused on hope for changes in education and the integration of creativity in multiple educational levels. Due to the pandemic and emergency shift to online education, inter-departmental collaboration developed. The professor also noted inequalities:

The digital equity gap has become more heightened during this period especially for students of color. The extremes of wealth and poverty are becoming more and more apparent. There are students who cannot complete their school work due to lack of access to internet or lack of adequate bandwidth (Wi-Fi). Some simply do not have 
devices... Some juggle working multiple jobs during the pandemic to make ends meet.

Of note was the increased burden on women. Both the focus on collaboration and concerns about inequity (Coyne et al. 2020) aligned with the literature.

The third story, which was that of the teacher specialist and program coordinator, examined disrupted hierarchy and redefining educational systems, the integration of students' voices in decisions, and the impacts of inequality. During the liminality of the emergency, the disrupted hierarchy created emergency teams that included all voices, especially those of students, who experienced the greatest impact. This shift spotlighted power dynamics:

Regarding the classroom, the pandemic has made visible-within our schools-conversations regarding the teacher-student power dynamic. Teachers are grappling with questions of context and meaning... teachers are re-examining their roles in relation to and with students in terms of motivation and relationship.

The literature aligns with this need to include parents' and students' voices in decisions (Midcalf and Boatwright 2020). The specialist included cautions about teachers' exhaustion and gaps in addressing teachers' needs, which aligned with literature about burnout (Coyne et al. 2020) and Zoom fatigue (Dogar et al. 2020).

The fourth story, which was that of the undergraduate professor (biology and anthropology), identified the need to build routines for students, preparation time, and student support. The professor addressed the challenges in shifting certain courses online, and how virtual experiences cannot effectively replace hands-on labs. Educator exhaustion emerged, again:

I didn't expect that teaching, my passion and joy, would begin to feel like drudgery. How could something I love so much be so unrewarding and relentless? I didn't realize how I much would miss the joy of in person interaction with my students. I didn't expect that my worries about "never doing enough" would become so amplified, that every time a student failed to show for a live session, I would question my value as a teacher.

This professor also noted their own increased creativity and the increased inclusion of students' feedback and students' voices.

The fifth story, from the learning centered TK-6 principal, had increased pandemic obligations, so they submitted a letter written to the parents. The focus was on communication and the liminality of the pandemic:

We do not expect parents to replicate being a teacher but we hope all that we're doing is providing families with opportunities to be creative... although we are not at school, we can still do school with your help and support.

Furthermore, this principal emphasized the need to build routines for students to develop a sense of normalcy and focused on both the joys of learning and the need for balance.

The sixth story, from the first-year special education teacher, looked at both what was clear in communication and what went unaddressed. In the face of liminality, this teacher took action. Differences in online teaching methodology quickly became apparent, since social-emotional learning did not translate well into the digital medium. The inequality 
of students accessing special education support also quickly became apparent but was balanced by deeper parent-teacher communication, which had been difficulty in the preCovid-19 special education work overload. Undaunted, this special education teacher concluded:

It has created an opportunity to re-think, re-connect, engage, and interact with my students and their parents in a completely different and new way. Teaching this year has taught me so many lessons and during that time, I have created a solid foundation of learning with my students. Although the future may be uncertain, I am excited for the opportunity to re-engage my students in new ways and continue the work that needs to be done. I know that they need it, and so do I.

Thus, the teacher ended by thoughtfully considering the positives of the experience.

The seventh story, that of the elementary teacher, was prefaced by recognizing inequality. Focused on pedagogy, the teacher noted how the established team developed tools to transition to online learning - and all that work was exhausting:

Teaching online is exhausting... there were different types of fatigue I was constantly battling - the exhaustion of looking at the computer all day... pouring through student work, holding students accountable, stressing about that one student that just won't show up, worrying about the students that are struggling, and trying to support families that were in different places in dealing with the crisis.

Noting the importance of data-driven instruction, learning continued to be student centered. This relied greatly on a strong collaborative team. This collaborating team was key to their success in transitioning to a digital platform. Learning also had specific expectations of parents, who needed coaching. However, despite regular connections with parents, students' performance varied:

Most students that succeeded easily in class, continued to do well, although some needed extra pushing because they dropped the ball completely. Some students that struggled with sensory and auditory issues performed better online and previous impediments to learning seemed to mostly disappear. Students who didn't have parents available to check in on them throughout the day struggled the most, along with students that struggled with sitting still for the lesson.

Finally, the teacher ended with a thoughtful reflection on student growth.

The eighth story, that of the parent with children in middle and high school, focused on the initial confusion until communication and routine academics were established, when "the magic happened". Academics were an important focus, but as time went on, academics were not enough:

This is getting old. School is so much more than academics. A speech and pragmatics session via zoom is just not cutting it. If it were just about academics I would think that homeschooling wins hands down; but watching my kids try to learn about interpersonal relationships, as my 6th grader needs help with, and my 12th-grade daughter yearning for some physical interaction with her friends, I think that physical school comes out ahead. 
Special education services were not as effective through a digital medium, and gaps occurred in the social-emotional support for students. They also recognized that pandemic learning is not homeschooling. While the district had done its best, online learning was not enough.

\section{Global focus}

After examining each text, notes were tallied, then clustered into themes. As such, established collaboration, connections, pedagogy, preparation, and teams were clear elements for preparation. Communication, handling liminality, routines, student voice, team support, student-centered learning, balance, data, and parent support were needed for successful maintenance. Inequality (along with lack of social-emotional connection, support, development, or provision) and reduced special education services undermined success.

\section{Discussion}

The discussion examines four major areas. These are the significance of a layered analysis, what did and did not work, mapping the findings, and study limitations.

\section{The layered analysis}

The first team's analysis was minimal but set the stage for broader discussions and future research. Ideally, the first team could have continued to identify codes and themes through NVivo. Stopping at the first read of the data resulted in an analysis that could never stand alone. However, this team also engaged in dialogic analysis (Bakhtin 1981) with the other teams after all of the initial analysis was completed, adding shared insight. This aided in testing the other teams' findings for dialogic validity (Anderson et al. 2007) while also supporting the culminating findings in the discussion. Finally, the first team developed a series of phenomenological interview questions. While interviews were not part of the study, the questions offered potential future research directions.

As a qualitative study, the second team's approach would typically have been the whole study. Aligned with narrative qualitative methods for coding and theme development, their findings could be considered solid and rigorous enough to complete the study (Rallis and Rossman 2011).

As a layered approach to the data, the third team-like the second team-could have held as stand-alone results. Taking a very different approach from the other teams, the data analysis looked deeply at each story, focusing on a voice-forward analysis.

While the second and third teams' analyses and findings might have stood alone, each identified patterns and themes unseen by the others. The strength of prismatic inquiry is in the layering of multiple perspectives on the data while the collaboration of researchers from multiple disciplines changed perspectives, mapping the phenomenon more thoroughly (Fisher 2016) rather than tracing a single path, no matter how many cycles each team chose to take. Prismatic inquiry also allowed the teams to come together as a whole to chart the research in several ways before recognizing the overall patterns and relationships.

The imbalance in the teams' analysis efforts was deliberate. The strength of prismatic inquiry is that multiple teams allowed one team to be weaker while the other two were stronger. Researchers short on time were part of the first team, and the approach was 
suggested by the team as the easiest to complete within the time frame. Researchers less experienced with a methodology were paired with more experienced researchers. Thus, prismatic inquiry also had space for teaching, learning, and practicing research methods.

\section{What worked? What did not work?}

When considering the questions given to the writers, the answer to what worked included foresight and preparation, resulting in more time to transition. Pairing this with supported collaboration, integrated flexibility, and technological fluency improved the transition for educators, which, in turn, improved the transition for students. Schools integrating parents' and students' voices in decision making also worked. Given enough time, some schools put systems in place to move learning forward. Effective communication and transparency greatly helped everyone adjust.

What did not work was when communication failed or educators were unfamiliar with technology. If educators struggled with software, then access was reduced for students, increasing the digital divide. Filling the social-emotional needs of students digitally was a repeated area of concern, which aligned with literature about pandemic mental health (Lakhan et al. 2020).

\section{The final map}

Reviewing the findings of all teams resulted in the following question: What are the necessary factors needed for students and educators to successfully navigate a transition to online learning? Students remain at the heart of the conversation, supported by leadership, teachers, parents, and the students themselves (Figure 2). Each partner in a student's education has their own needs, based on position and role.

Leadership needs to be learning centered (DuFour 2002) and look ahead at how worldwide, national, or local events can have an impact on education. This includes being able to pivot quickly in times of emergency (Coyne et al. 2020). Dismantling the traditional patriarchal hierarchy empowers educators', parents', and students' voices, which aids in developing effective systems for learning (Harper 2020). Collaboration both professionally and with educational teams is also important for leaders, because leadership needs to be part of a professional learning community (Nordmann et al. 2020). Leadership's role for clear communication with parents, teachers, and students was key, as seen in other studies (Coyne et al. 2020).

The educator needs an authentic collaborative team to support, share, and build ideas (DuFour 2002). The literature recognizes the need for professional learning communities (Nordmann et al. 2020) and the importance of collaboration across disciplines (Hunger and Schumann 2020). However, the connections between how well-established collaborative teams worked seamlessly to produce a faster and stronger educational pivot while reducing the heavy load educators were already carrying. This emerged clearly in two stories that modeled excellent transitions.

Educators also needed preparation time for teaching, reflecting, and learning. This was true for the initial transition but is also true outside of pandemic education. It takes time to develop curriculum and to develop as an educator. This is equally important when developing engaging online distance instruction (Kaup et al. 2020). Also important for educators is training and experience in using technology in a way that transmits knowledge to parents and students so they also have knowledge, experience, and access. Pairing this with 
flexibility (Will 2020) improves educators' ability to adapt. Finally, effective communication with leadership and with parents and students, often through an online platform, is as important as having the data to drive instruction (Dobrilă 2020).

Parents need to be part of the educational collaboration (Ray 2020). They need to know how to support their students, and need support in handling the multiple stresses they, themselves, may be under due to the pandemic (Chaney 2020). This includes supports for navigating the liminality of an emergency as well as resources they can access for support; communication with leadership, teachers, and students; understanding of the goals and purposes behind education; and recognition that, as a child's first teacher, their behaviors, support, attitude, and biases have an impact on their child's learning. Students need socialemotional support and skills; a voice in their learning; connections with each other, their parents, and educators (e.g., teachers, professors, school leadership, and educational staff); and to take ownership of their learning.

All four participants in this equation-leadership, educators, parents, and studentsneed, in differing ways (a) connection, (b) voice, (c) social-emotional skills, and (d) academic knowledge. While these four things looked slightly different from each perspective,

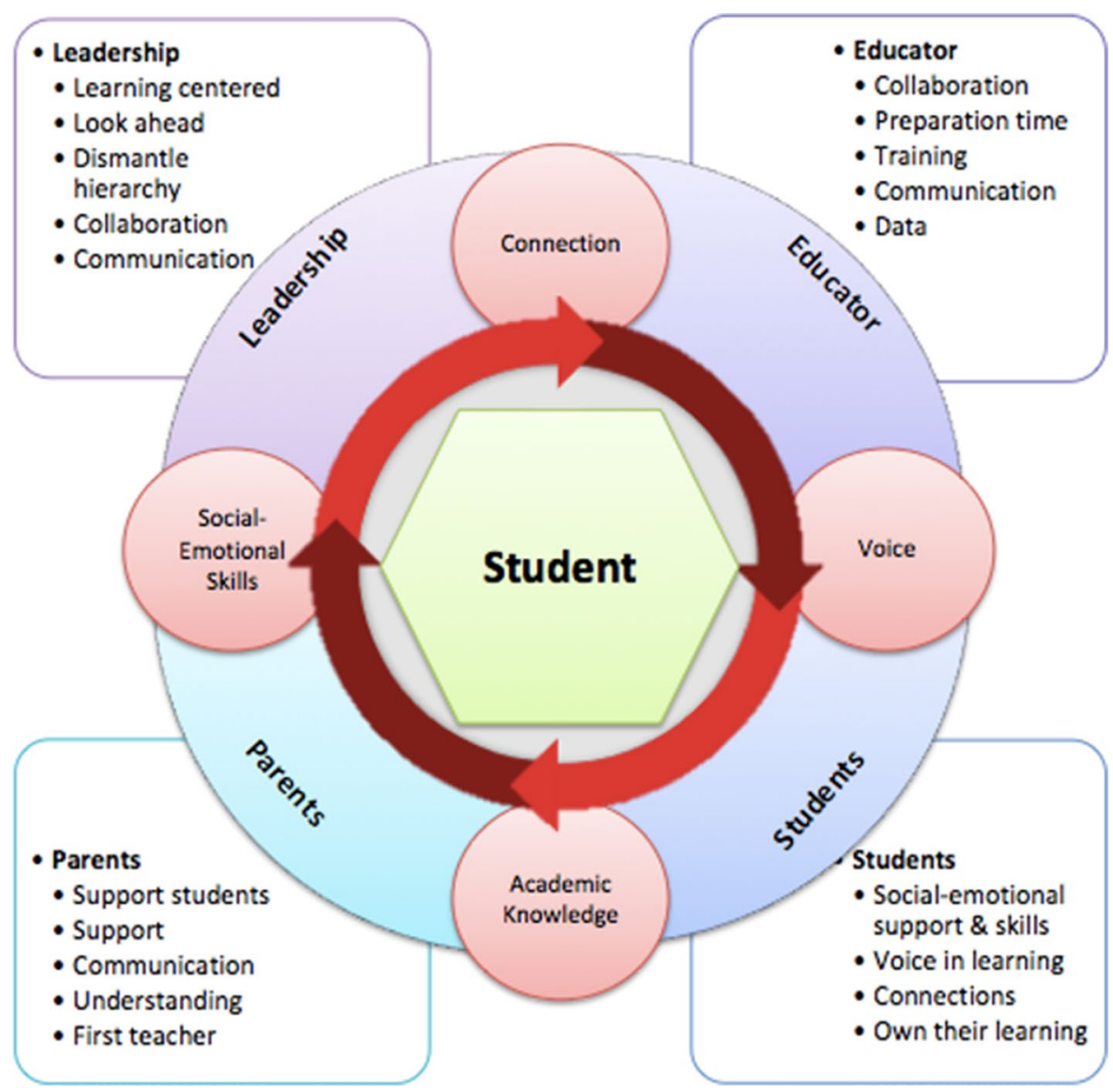

Figure 2 Findings 
the need for connection supported each person's strengths for human connection and authentic professional or educational collaboration. All perspectives needed an authentic voice in not only situations of change and liminality but also the educational system. The development of explicit tools for social-emotional skills and the handling of emotions, anxiety, stress, and more was needed at all levels to handle change. Finally, academic knowledge was needed to aid in support, application, decision-making, and learning.

In the case of higher education, the student loses their parents' support in the equation, taking on the dual adult role of student and supporter. The role of family can vary widely, ranging from supporting to missing entirely (resulting in students with multiple jobs trying to pay for their own education) to having the student in an additional supporting role for family members. Leadership is still important but becomes more distant for the student, creating the illusion that the only parts of this dynamic are the student and the professor.

Finally, of note is that limiting the study to the second team's narrative approach would have resulted in solid findings. However, due to the underrepresentation of vulnerable populations in the study, it would have missed the identifications of the impacts of in/equity, which emerged in the third team's analysis. Impacts of inequity on vulnerable populations show up throughout the literature, such as in language (James and Thériault 2020), economics (Harper 2020), culture (Harper 2020), health (Jacobson et al. 2020), and disability (James and Thériault 2020). Any of these can have an impact on digital access (Coyne et al. 2020). Similarly, when one piece of the support system for a student is missing, this weakens the student's access to equitable education, which is then exacerbated during pandemic education when "school" is more difficult to access.

\section{Limitations}

This work was subject to four limitations. First, data analysis was limited to eight participants. Although this number provided great insight into the personal lived experiences of these individuals, the small sample size limits the generalizability of the results. Second, participants lacked certain forms of diversity, such as higher education administrators, fathers, students, and limited representation of marginalized populations. Further research should include a wider variety of backgrounds. Third, the open-ended prompt was both a benefit and a limitation. By leaving it loosely structured, participants were free to interpret the prompt and respond according to personal resonance; however, this also meant that responses varied widely, making analysis interesting but challenging. Finally, the timing of the study focused only on the initial pandemic transition. This provided excellent insight into early experiences and processes but did not include later changes.

\section{Conclusion}

Examining pandemic learning from the Covid-19 emergency from multiple perspectives and levels offers a unique perspective on what is needed across all levels for a successful transition. Certain commonalities (e.g., putting students at the center of the conversation and the need for connection, voice, social-emotional skills, and academic knowledge by all parts of the educational equation, as well as unique needs for each role) are needed in order to flourish in adversity. Furthermore, higher education can learn from the fourpoint support the K-12 student has by recognizing that higher education is more than the 
student-professor dynamic. For higher education, the student may or may not have the supports of a parent, or may themselves be in the role of supporter for their own children, undermining the strength of this dynamic. Similarly, K-12 educators need to remember that students who do not have the parental piece in place suffer from increased inequality. This is also true when students do not have all they may need to support their own education. Educators at all levels of education need to be aware of how imbalance leads to further inequality; of how, whether in times of normalcy or of liminality, disruption, and change, diverse needs require differentiated approaches; and that all levels need the same things to be successful.

\section{References}

Achieng-Evensen, C., Fisher, M. E., McKee, A., Gomez, A., Stockbridge, K., Dorner, M. A., \& Maghzi, K. S. (2017). Changing educational lenses: Prismatic collaborative inquiry. CCTE News: Newsletter for the California Council on Teacher Education, 28(1), 24-27.

Anderson, G. L., Herr, K., \& Nihlen, A. S. (2007). Studying your own school: An educator's guide to practitioner action research (2nd ed.). Thousand Oaks, CA: Corwin Press. https://www.corestandards.org.

Bakhtin, M. M. (1981). The dialogic imagination: Four essays by M. M. Bakhtin (M. Holquist \& C. Emmerson, Trans.). Minneapolis, MN: University of Minnesota Press.

Breton, A. (1936). What is surrealism? (D. Gascoyne, Trans.). London: Faber \& Faber.

CCSSSO [Council of Chief State School Officers] \& NGA Center [National Governors Association Center] (2010). Common core state standards initiative. Washington, DC: National Governors Association Center for Best Practices (NGA Center).

Chaney, C. (2020). Family stress and coping among African Americans in the age of Covid-19. Journal of Comparative Family Studies, 51(3/4), 254-273. https://doi.org/10.3138/jcfs.51.3-4.003.

Coyne, C., Ballard, J. D., \& Blader, I. J. (2020). Recommendations for future university pandemic responses: What the first Covid-19 shutdown taught us. PLoS Biology, 18(8), 1-6. https://doi.org/ 10.1371/journal.pbio.3000889.

De Giusti, A. (2020). Policy brief: Education during Covid-19 and beyond. Revista Iberoamericana de Tecnología en Educación y Educación en Tecnología, 26, e12-e12.

Deleuze, G., \& Guattari, F. (1987). A thousand plateaus: Capitalism and schizophrenia. Minneapolis, MN: University of Minnesota Press.

Dobrilă, M. C. (2020). Legal aspects regarding online learning process for students at university and digital education in European Union: Different Life, challenges and the ability to continue education during the pandemic caused by coronavirus (Covid-19). Revista Românească pentru Educaţie Multidimensională [Romanian Journal for Multidimensional Education], 12, 130-137. https://doi. org/10.18662/rrem/12.2Sup1/298.

Dogar, A. A., Shah, I., Ali, S. W., \& Ijaz, A. (2020). Constraints to online teaching in institutes of higher education during pandemic Covid-19: A case study of CUI, Abbottabad Pakistan. Revista Românească pentru Educaţie Multidimensională [Romanian Journal for Multidimensional Education], 12, 12-24. https://doi.org/10.18662/rrem/12.2Sup1/285.

DuFour, R. (2002). The learning centered principal. Educational Leadership, 59(8), 12-15.

Ede, A. (2006). Scripted curriculum: Is it a "prescription for success?" Childhood Education, 83(1), 29-32.

Eisner, E. W. (1991). The enlightened eye: Qualitative inquiry and the enhancement of educational practice. New York, NY: Macmillan.

Fisher, M. E. (2013). Foundations of contemporary surrealism for educational research [Conference presentation]. American Educational Research Association Conference, San Francisco, CA.

Fisher, M. E. (2016). Here there be dragons: Initially developing prismatic theory and prismatic inquiry [Conference presentation]. American Education Research Association Conference, Washington, DC.

Glaser, B. G. A., \& Strauss, A. L. A. (1967). The discovery of grounded theory: Strategies for qualitative research. Piscataway, $\mathrm{NJ}$ : Aldine.

Harper, S. R. (2020). Covid-19 and the racial equity implications of reopening college and university campuses. American Journal of Education, 127(1), 153-162. https://doi.org/10.1086/711095. 
Hunger, J., \& Schumann, H. (2020). How to achieve quality assurance, shared ethics and efficient teambuilding? Lessons learned from interprofessional collaboration during the Covid-19 pandemic. GMS Journal for Medical Education, 37(7), 1-7. https://doi.org/10.3205/zma001372.

Jacobson, T. A., Smith, L. E., Hirschhorn, L. R., \& Huffman, M. D. (2020). Using implementation science to mitigate worsening health inequities in the United States during the Covid-19 pandemic. International Journal for Equity in Health, 19(1), 1-6. https://doi.org/10.1186/s12939-020-01293-2.

James, N., \& Thériault, V. (2020). Adult education in times of the Covid-19 pandemic: Inequalities, changes, and resilience. Studies in the Education of Adults, 52(2), 120-133. https://doi.org/10. 1080/02660830.2020.1811474.

Johnson, N., Veletsianos, G., \& Seaman, J. (2020). US faculty and administrators' experiences and approaches in the early weeks of the Covid-19 Pandemic. Online Learning, 24(2), 6-21.

Kaup, S., Jain, R., Shivalli, S., Pandey, S., \& Kaup, S. (2020). Sustaining academics during Covid-19 pandemic: The role of online teaching-learning. Indian Journal of Ophthalmology, 68(6), 12201221. https://doi.org/10.4103/ijo.IJO_1241_20.

Knysh, O., \& Dudziak, O. (2020). Overcoming the challenges: The impact of Covid-19 on agricultural higher education in Ukraine. Revista Românească pentru Educaţie Multidimensională [Romanian Journal for Multidimensional Education], 12, 162-167. https://doi.org/10.18662/rrem/12.2Sup1/302.

Lakhan, R., Agrawal, A., \& Sharma, M. (2020). Prevalence of depression, anxiety, and stress during Covid19 pandemic. Journal of Neurosciences in Rural Practice, 11(4), 519-525. https://doi.org/10.1055/s0040-1716442.

Leavy, P. (2009). Method meets art: Arts-based research practice. New York, NY: Guilford Press.

Loda, T., Löffler, T., Erschens, R., Zipfel, S., \& Herrmann-Werner, A. (2020). Medical education in times of Covid-19: German students' expectations: A cross-sectional study. PLOS ONE, 15(11), 1-11. https:// doi.org/10.1371/journal.pone.0241660.

Midcalf, L., \& Boatwright, P. (2020). Teacher and parent perspectives of the online learning environment due to Covid-19. Delta Kappa Gamma Bulletin, 87(1), 24-34.

Molea, R., \& Năstasă, A. (2020). How Romanian higher education institutions have adapted to online learning process in the Covid-19 context through a student's eye. Revista Românească pentru Educaţie Multidimensională [Romanian Journal for Multidimensional Education], 12, 175-181. https://doi.org/ 10.18662/rrem/12.2Sup1/304.

Murphy, M. P. (2020). Covid-19 and emergency eLearning: Consequences of the securitization of higher education for post-pandemic pedagogy. Contemporary Security Policy, 31(3), 492-505. https://doi.org/ 10.1080/13523260.2020.1761749.

Nordmann, E., Horlin, C., Hutchison, J., Murray, J.-A., Robson, L., Seery, M. K., \& MacKay, J. R. D. (2020). Ten simple rules for supporting a temporary online pivot in higher education. PLoS Computational Biology, 16(10), 1-18. https://doi.org/10.1371/journal.pcbi.1008242.

Rallis, S. F., \& Rossman, G. B. (2011). Learning in the field: An introduction to qualitative research. Thousand Oaks, CA: Sage Publications.

Ray, K. (2020). The evolution of education: The new normal could be better than ever. Tech \& Learning. https:// www.techlearning.com/how-to/the-evolution-of-education-the-new-normal-could-be-better-than-ever

Rittel, H. W. J., \& Webber, M. M. (1972). Dilemmas in a general theory of planning. Berkeley, CA: Institute of Urban and Regional Development, University of California.

Saldaña, J. (2013). The coding manual for qualitative researchers. Thousand Oaks, CA: Sage Publications.

Shaffer, G. (2001). Cookie cutter education. The Humanist, 6(3), 14-19.

Stanley, L. (2001). Mass-observations fieldwork methods. In P. Atkinson, A. Coffey, S. Delamont, J. Lofland, \& L. Lofland (Eds.), Handbook of ethnography (pp. 92-108). Thousand Oaks, CA: Sage Publications.

Stern, P. N. (2007). On solid ground: Essential properties for growing grounded theory. In A. Bryant \& K. Charmaz (Eds.), The handbook of grounded theory (pp. 114-126). Thousand Oaks, CA: Sage Publications.

Will, M. (2020). Six lessons learned about better teaching during the pandemic. Education Week, 40(12), $18-21$.

Yusoff, M. S. B., Hadie, S. N. H., Mohamad, I., Draman, N., Ismail, M. A.-A., Rahman, W. F. W. A., et al. (2020). Sustainable medical teaching and learning during the Covid-19 pandemic: Surviving the new normal. Malaysian Journal of Medical Sciences, 27(3), 137-142. https://doi.org/10.21315/mjms2020. 27.3.14.

Publisher's Note Springer Nature remains neutral with regard to jurisdictional claims in published maps and institutional affiliations. 
Marni E. Fisher currently teaches at Saddleback College and has 24 years of experience in education, spanning K-8, leadership, undergraduate, and graduate education. She developed prismatic theory and prismatic inquiry for educational research. She has presented more than 40 times at conferences and published a handful of articles and book chapters. Her second book, Lessons from the Transition to Pandemic Education, will be published in fall 2021.

Meredith A. Dorner is a professor at Irvine Valley College with advanced degrees in biology, anthropology, and education, with a research focus on science education. As a tenured professor at a community college, in addition to teaching college-level biology and anthropology courses, she has extensive experience working with collaborative qualitative and quantitative research teams.

Kimiya Sohrab Maghzi's research foci are disability studies, DisCrit, and critical race theory, and her research method expertise is in phenomenology. A tenure-track professor at the University of Redlands who teaches graduate students, and the mother of two small children, she has published several of news articles and book chapters.

Charlotte Achieng-Evensen is a K-12 educator and academic. Her scholarly work centers on the intersections of Indigenous philosophies and colonization, culturally responsive teaching and research, and professional learning for secondary teaching practices. She has been a K-12 practitioner for 21 years. She serves as a district teacher specialist and teaches university teacher education courses at Chapman University.

Leslie C. Whitaker is an experienced K-5 teacher of 16 years who has been the teacher of the year, was EISS certified, served as a mathematics coordinator at the Orange County Department of Education, coached math as a teacher on special assignment for 3 years, taught numerous workshops for teachers, and wrote three books. In 2020, she was a state finalist for a national honor in math and science education award.

Fran Hansell has four degrees and was a National Board Certified teacher. She is a passionate educator who has taught grades K-6 general and special education throughout California as well as served as an assistant principal and principal in Title 1 and GATE elementary and K-8 schools. She advocates for all students succeeding in a global world and believes strengths-based approaches build the capacity from within an organization to empower staff and students to be the best version of themselves.

James St. Amant is an elementary special education teacher in the Apple Valley Unified School District. His background includes a bachelor of arts in psychology, a master of arts in marriage and family therapy, and an education specialist credential.

Susan M. Gapinski is a union iron worker. She is highly involved in politics, in between going to school, working, and raising five children with her husband of 29 years. 